\title{
Variability in the sonic muscles of the Lusitanian toadfish (Halobatrachus didactylus): acoustic signals may reflect individual quality
}

\author{
M.C.P. Amorim, R.O. Vasconcelos, and B. Parreira
}

\begin{abstract}
Animal vocalizations are good examples of signals that have been shaped by sexual selection and often contribute to resolve contests or the choice of mates. We relate the mass of the sound-producing muscles of a highly vocal fish species, the Lusitanian toadfish (Halobatrachus didactylus (Bloch and Schneider, 1801)), with the sender's physical features, such as body size, and reproductive and body condition. In this species, both sexes are known to emit sounds during agonistic interactions and males rely on their mate attraction vocalizations to reproduce. Sonic muscles were highly variable among males $(\mathrm{CV}=40 \%)$ and females $(\mathrm{CV}=33 \%)$ and showed sexual dimorphism. Regression analysis showed that variability in the sonic muscles was best explained by total length and fish condition in males and females. Liver mass in both genders, and the mass of the testes accessory glands, also explained sonic muscle variability. These variables explained $96 \%$ and $91 \%$ of the sonic muscle mass variability in males and females, respectively. As in teleost fishes sonic muscle mass correlates to particular sound acoustic features, we propose that in the Lusitanian toadfish sounds can inform the receiver about the sender's quality, such as body size and condition, which are critical information in contests and mate choice.

Résumé : Les vocalisations animales sont de bons exemples de signaux qui ont été façonnés par la sélection sexuelle et qui servent souvent à déterminer l'issue des joutes ou le choix de partenaires. Nous mettons en relation la masse des muscles producteurs de sons d'un poisson à vocalisations fréquentes, le crapaud lusitanien (Halobatrachus didactylus (Bloch et Schneider, 1801)), avec les caractéristiques physiques de l'émetteur, telles que la taille du corps et les conditions reproductive et corporelle. Chez cette espèce, les deux sexes sont reconnus pour émettre des sons durant les interactions agressives et les mâles dépendent des vocalises d'attraction de leur partenaire pour la reproduction. Les muscles du son sont très variables chez les mâles $(\mathrm{CV}=40 \%)$ et les femelles $(\mathrm{CV}=33 \%)$ et affichent un dimorphisme sexuel. Une analyse de régression montre que la variabilité des muscles du son s'explique le mieux par la longueur totale et la condition des poissons mâles et femelles. La masse du foie des deux sexes et la masse des glandes accessoires des testicules sont aussi des variables explicatives de la variabilité des muscles du son. Ces variables expliquent respectivement $96 \%$ et $91 \%$ de la variabilité de la masse des muscles du son chez les mâles et les femelles. Comme chez les téléostéens la masse des muscles du son est en corrélation avec certaines caractéristiques acoustiques particulières, nous croyons que chez le crapaud lusitanien, les sons peuvent renseigner l'auditeur sur la qualité de l'émetteur, en particulier sur la taille du corps et sur la condition corporelle, qui sont des informations essentielles dans les joutes et le choix des partenaires.
\end{abstract}

[Traduit par la Rédaction]

\section{Introduction}

Exaggerated sexual secondary male traits have evolved under sexual selective pressure through male-male competition, mate choice, or both (Andersson 1994). Animal vocalizations are good examples of such traits (Andersson 1994; Bradbury and Vehrencamp 1998), and empirical evidence has shown that acoustic signals may influence the outcome of male contests or be subject to female preference in vari-

Received 15 January 2009. Accepted 29 May 2009. Published on the NRC Research Press Web site at cjz.nrc.ca on 30 July 2009.

M.C.P. Amorim. ${ }^{1}$ Unidade de Investigação em Eco-Etologia, Instituto Superior de Psicologia Aplicada, Rua Jardim do

Tabaco 34, 1149-041 Lisboa, Portugal.

R.O. Vasconcelos. Departamento de Biologia Animal e Centro de Biologia Ambiental, Faculdade de Ciências da Universidade de Lisboa, Bloco C2 Campo Grande, 1749-016 Lisboa, Portugal. B. Parreira. Instituto Gulbenkian de Ciência, Rua da Quinta Grande, n 6, 2780-156 Oeiras, Portugal.

${ }^{1}$ Corresponding author (e-mail: amorim@ispa.pt). ous taxa (e.g., Davies and Halliday 1978; Hasselquist et al. 1996; Márquez et al. 2008).

In order for communication to be adaptive, signals should convey honest information. Signals are expected to be reliable if they are costly, and costly signals are likely to impose even more constraints to animals in poor condition (Zahavi 1975; Grafen 1990). Alternatively, honest signals can be relatively cost-free if signallers and receivers share a common interest (in this case any signaller can do it), or if physical or physiological constraints determine the quality of the signal (indices of quality) (reviewed in Maynard Smith and Harper 2003). Vocal displays by ectothermic vertebrates are thought to be one of the most energetically costly activities (Taigen and Wells 1985; Prestwich 1994; but see Amorim et al. 2002), and costs are determined mostly by duration, amplitude, and rate of calling (Prestwich 1994). Hence, these features can potentially be honest indicators of the sender's quality. Further, some acoustic features of vocal displays are dependent on male's characteristics, such as size, being a reliable predictor of fighting ability or mating success (e.g., Bee et al. 1999; Márquez et al. 2008). 
Many species of teleost fish use acoustic signals during male-male competition and mate attraction (Ladich 2004; Amorim 2006), and are thereby expected to be subject to sexual selection pressure (Andersson 1994). Although fish sounds do not seem energetically expensive (Amorim et al. 2002), calling activity seems limited by physiological constraints such as fatigue resistance (Mitchell et al. 2008), making a high rate of sound production physiologically challenging. Some acoustic parameters are also intimately related to increased fish size, such as lower sound dominant frequency, higher sound amplitude, and increased pulse duration observed in larger fish (Myrberg et al. 1993; Connaughton et al. 2000). This evidence further suggests that calling rate and particular acoustic parameters can honestly signal the sender's quality in male contests and in courtship.

A major mechanism of sound production in fish is the rhythmical vibration of the swim bladder by the action of specialized rapid sonic muscles (Ladich and Fine 2006). In many species, sonic muscles show sexual dimorphism and hypertrophy during the mating season, with males showing heavier sonic muscles, with higher number of muscle fibres, and differences in the fine structure of muscle fibres (Fine et al. 1990; Brantley et al. 1993a; Connaughton et al. 2000; Modesto and Canário 2003a). Seasonal hypertrophy and sexual dimorphism of sonic muscles are mediated by androgens (Fine and Pennypacker 1986; Brantley et al. 1993b; Connaughton et al. 2000), which also modulate courtship behaviour (Knapp et al. 1999). Differences in the mass of sonic muscles, and concomitant morphological changes, thus seem to parallel the increase in vocal output by males during the breeding season (Amorim et al. 2006).

In this study we examine the possibility that fish acoustic signals can indicate the sender's quality by relating the mass of the sound-producing muscle of a highly vocal fish species with its physical features. In a first step we investigated if certain external features, such as fin size and mouth width, that are associated with agonistic displays (Vasconcelos and Ladich 2008) show sexual dimorphism. This part of the study was carried out under the premise that these could potentially be sexually selected traits and could give information on the quality of an individual (e.g., Engen and Folstad 1999). Secondly we explored the relation between sonic muscle mass and several traits, such as any dimorphic external feature, body size, reproductive status, and body condition. We use the Lusitanian toadfish (Halobatrachus didactylus (Bloch and Schneider, 1801)) (Batrachoididae) as a model because they are versatile and prolific sound producers, and males show a pronounced increase in the sonic muscles mass and sonic activity during the breeding season (Modesto and Canário 2003a; Amorim et al. 2006; Amorim et al. 2008). Indeed, batrachoidids, including the Lusitanian toadfish, have been models for studies of acoustic communication, as they show prolonged bouts of vocal activity, males nest in shallow water and are relatively easy to access, react to playback experiments, and have been subject to a large body of neurobiological studies (Cohen and Winn 1967; Barimo and Fine 1998; Bass and McKibben 2003; Modesto and Canário 2003a, 2003b; Remage-Healey and Bass 2005). Furthermore, batrachoidids present intra- and inter-sexual dimorphism in the brain, sonic muscle, and vocal behaviour, with territorial type I males showing reproductive singing behaviour. whereas type II males (sneakers) and females only produce agonistic calls (Bass and McKibben 2003).

\section{Material and methods}

\section{Study species}

During the breeding season (May-July), male Lusitanian toadfish emit advertisement calls (boatwhistles) to attract females to the nests that they defend in estuarine shallow waters (dos Santos et al. 2000; Amorim et al. 2006). Males mate with several females, and care for the fertilized eggs attached to the nest's ceiling until the young are free-swimming (dos Santos et al. 2000). Besides the boatwhistle, three other sound types are commonly produced by nesting males: grunt trains, long grunt trains, and double croaks, as well as other less frequent sound emissions such as croaks and mixed croak-grunt calls (Amorim et al. 2008). Similar to other batrachoidids, this species presents sexual polymorphism with two male morphotypes that differ in morphometric and endocrine characteristics, as well as in vocal behaviour. Nest-guarding males (type I) differ from sneaking males (type II) by having smaller testes (sevenfold), larger accessory glands (threefold; the accessory glands are part of the male reproductive apparatus, secrete mucosubstances, and are connected to the spermatic duct), and higher (sixfold) 11-ketotestosterone levels (Modesto and Canário $2003 a, 2003 b$ ). Females and sneaker males are only known to emit grunt trains and females show lighter sonic muscles than males, with type II males presenting intermediate sonic muscle mass to females and type I males (Modesto and Canário 2003a). Sonic muscles of type I males, but not of type II males or of females, experience hypertrophy during the breeding season (Modesto and Canário 2003a), mirroring an increase in vocal activity (Amorim et al. 2006).

\section{Specimen and sample collection}

Fish samples were collected by trawling, angling, and hand capture by local fishermen during the months of June, August, and September in 2003 and from April to September in 2004 from Tagus estuary, areas of Montijo $\left(38^{\circ} 42^{\prime} \mathrm{N}, 8^{\circ} 58^{\prime} \mathrm{W}\right)$ and Barreiro $\left(38^{\circ} 39^{\prime} \mathrm{N}, 9^{\circ} 04^{\prime} \mathrm{W}\right)$. Specimens were kept frozen in the laboratory until measured. This sample included both reproductive ( $40.5 \%$ of males and $76.5 \%$ of females) and nonreproductive specimens, since the breeding season typically lasts from May to July (Modesto and Canário 2003a).

To investigate the existence of sexual dimorphism in external morphological traits involved in agonistic displays, we took the following measurements: mouth width (MW, maximum width of the lower lip); pectoral fin length (PL, base of the pectoral fin to the tip of its largest ray); ventral fin length (VL, base of the ventral fin to the tip of its largest ray); and dorsal fin length (DL, length of the largest fin ray of the first dorsal fin). All mouth and fin measurements were made to the nearest millimetre with callipers.

Gonad $\left(M_{\mathrm{G}}\right.$; Fig. $\left.1 \mathrm{~A}\right)$, accessory glands (in males, $M_{\mathrm{AG}}$; Fig. 1A), and liver $\left(M_{\mathrm{L}}\right)$ mass were tallied to the nearest milligram. Both sonic muscles, which are embedded in the sides of the swim bladder (Figs. 1A, 1B), were gently cut from the swim-bladder wall with a pair of fine dissection scissors and were also weighed $\left(M_{\mathrm{SM}}\right)$ to the nearest milligram. We also obtained total length (TL), measured to the 
Fig. 1. (A) Dissected type I male Lusitanian toadfish (Halobatrachus didactylus) showing the swim bladder (SB), the gonads (G), and the accessory glands (AG). (B) Dorsal view of one lobe of the swim bladder depicting the embedded sonic muscle (SM).

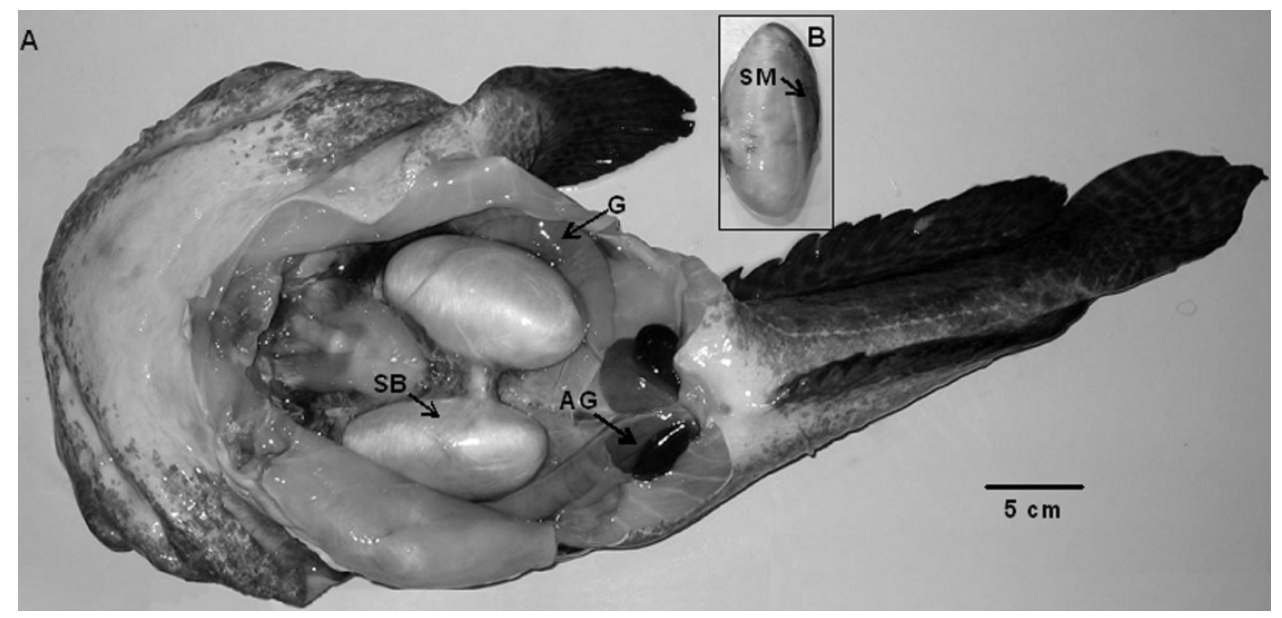

nearest millimetre, and eviscerated body mass $\left(M_{\mathrm{E}}\right)$, measured to the nearest gram.

Males $(n=79)$ used in this study were $33.04 \pm 5.9 \mathrm{~cm}$ TL (mean \pm SD; range 17.4-44.5 cm TL) and weighed $629 \pm$ $303.1 \mathrm{~g}$ (range 84-1421 g) in eviscerated mass, whereas females $(n=34)$ were $27.02 \pm 3.5 \mathrm{~cm}$ TL (range 18.7$33.8 \mathrm{~cm} \mathrm{TL}$ ) and weighed $304 \pm 109.0 \mathrm{~g}$ (range 107-547 g) in eviscerated mass. All males were likely type I males. Type II males were not considered in this analyses because they were captured in very small quantities $(n=2)$.

\section{Statistical analysis}

We ran analysis of covariance (ANCOVA) to explore the existence of differences between sexes for fins (PF, VF, and $\mathrm{DF}$ ) and mouth width (MW) variables, controlling for body size (TL). Initial analyses included an interaction term, which was subsequently removed because it was not significant in all cases. We $\log _{10}$-transformed the dependent variables (fin length and mouth width) and TL to meet the assumptions of the models. Kolmogorov-Smirnov tests confirmed that the assumption of normality was met in all analyses.

To quantify sonic muscle mass variability we calculated the mean $\pm \mathrm{SD}$ (range), as well as the coefficient of variations $(\mathrm{CV}=(\mathrm{SD} / \mathrm{mean}) \times 100)$, for males and females. Sexual dimorphism in sonic muscle mass was tested with ANCOVA with $\log M_{\mathrm{SM}}$ as the response variable, sex as the factor, and $\log M_{\mathrm{E}}$ as the covariate. As above, the interaction term was not included in the final model because it was not significant.

We fitted a multiple regression model with a stepwise procedure to explain variation in sonic muscle mass (dependent variable). We considered VL and DL in the initial model, as they were sexually dimorphic (see results). We included TL in the model as a metric of body size. We also considered the mass of gonads, accessory glands (in males), and liver as independent variables. We controlled for the influence of body size on $M_{\mathrm{G}}$ by using residuals of the simple linear regression of $M_{\mathrm{G}}$ on $M_{\mathrm{E}}\left(\mathrm{RM}_{\mathrm{G}}\right)$ in the multiple regression model. We considered the eviscerated mass $\left(M_{\mathrm{E}}\right)$ to represent body mass because it is independent of $M_{\mathrm{G}}, M_{\mathrm{AG}}$, and $M_{\mathrm{L}}$. Likewise, we controlled for the influence of size on variations of $M_{\mathrm{AG}}$ (males only) and $M_{\mathrm{L}}$ by regressing these variables on $M_{\mathrm{E}}\left(\mathrm{RM}_{\mathrm{AG}}\right.$ and $\mathrm{RM}_{\mathrm{L}}$, respectively). Similarly, we used the residuals of the regression of $M_{\mathrm{E}}$ on TL (COND) as a metric of condition. Positive residuals indicate that males are heavier than predicted and have good body condition, whereas negative residuals represent animals with poor condition. We $\log _{10}$-transformed TL and mass data both in the simple and in the multiple linear regressions to meet the assumptions of normality and to linearize allometric relationships. Separate models were fitted for males and females. All model assumptions were met for both male and female models. All model residuals were normally distributed. Additional residual analysis was performed using DurbinWatson statistics (males $=2.08$ and females $=1.83$ ), residuals autocorrelation plots, and multicolinearity tests between all used variables.

All statistical analyses were performed using $\mathrm{R}$ version 2.8.0 ( $\mathrm{R}$ Foundation for Statistical Computing, Vienna, Austria) and SPSS version 16.0 for Windows (SPSS Inc., Chicago, Illinois, USA).

\section{Results}

\section{External morphological sexual dimorphism}

Mouth width and pectoral fin length did not differ between males and females (ANCOVA; MW: $F_{[1,110]}=2.10$, $P>0.05$; PF: $\left.F_{[1,110]}=2.59, P>0.05\right)$, but the ventral and the dorsal fins were longer in females, controlling for body length (ANCOVA; VF: $F_{[1,110]}=14.32, P<0.001$; DF: $\left.F_{[1,76]}=5.74, P<0.05\right)$ (Fig. 2 ). The covariate TL had a significant effect on mouth width and fin length, which increased with body length (ANCOVA; MW: $F_{[1,110]}=$ 834.65; PF: $F_{[1,110]}=494.76$; VF: $F_{[1,110]}=315.28 ; \mathrm{DF}:$ $F_{[1,76]}=106.24, P<0.001$; Fig. 2).

\section{Sonic muscle variability}

Sonic muscle mass showed considerable variation among males $(11.09 \pm 4.43 \mathrm{~g}$, range $1.68-20.93 \mathrm{~g})$ and among females $(5.26 \pm 1.75 \mathrm{~g}$, range $1.74-8.71 \mathrm{~g})$. Coefficient of variation for this parameter was $39.9 \%$ in males and $33.2 \%$ in females. Moreover, sonic muscle mass showed significant dimorphism between sexes (Fig. 3), controlling for body mass (ANCOVA; sex: $F_{[1,110]}=21.37, P<0.001 ; M_{\mathrm{E}}$ : $\left.F_{[1,110]}=1549.19, P<0.001\right)$. 
Table 1. Results of the multiple regression analyses of sonic muscle mass ( $\log M_{\mathrm{SM}}$ ) on total length ( $\log \mathrm{TL})$, condition $(\mathrm{COND})$, residual accessory gland mass $\left(\mathrm{RM}_{\mathrm{AG}}\right.$; males only), and residual liver mass $\left(\mathrm{RM}_{\mathrm{L}}\right)$ for male and female Lusitanian toadfish (Halobatrachus didactylus).

\begin{tabular}{llclrl}
\hline Gender & Coefficients & Estimate & SE & \multicolumn{1}{l}{$t$} & $P$ \\
\hline Males $(n=79)$ & Intercept & 6.76 & 0.22 & -30.72 & $<0.001$ \\
& log TL & 2.60 & 0.06 & 40.75 & $<0.001$ \\
& COND & 0.12 & 0.01 & 9.21 & $<0.001$ \\
& RM $_{\mathrm{AG}}$ & 0.06 & 0.01 & 4.59 & $<0.001$ \\
& RM $_{\mathrm{L}}$ & 0.03 & 0.01 & 2.25 & $<0.05$ \\
Females $(n=34)$ & Intercept & -6.47 & 0.48 & -13.59 & $<0.001$ \\
& log TL & 2.45 & 0.14 & 16.97 & $<0.001$ \\
& COND & 0.08 & 0.02 & 4.14 & $<0.001$ \\
& RM $_{\mathrm{L}}$ & 0.06 & 0.02 & 2.88 & $<0.01$ \\
\hline
\end{tabular}

Fig. 2. Relation between fin length (VF, ventral fin; DF, dorsal fin; $\mathrm{PF}$, pectoral fin) and total length (TL), and between mouth width (MW) and TL, in male (O) and female (O) Lusitanian toadfish (Halobatrachus didactylus).


The best multiple regression model fitted with a stepwise procedure (males: $F_{[4,74]}=447.4, P<0.001, r^{2}=0.96$; females: $\left.F_{[3,30]}=105.6, P<0.001, r^{2}=0.91\right)$ included TL, condition, and liver mass $\left(\mathrm{RM}_{\mathrm{L}}\right)$ as explanatory variables in both male and female models (Table 1). The residual accessory gland mass $\left(\mathrm{RM}_{\mathrm{AG}}\right)$ was also included as a significant independent variable in the final model for males. Body length was the first variable included in the models and explained most of the variance of sonic muscle mass both for males $(88.7 \%)$ and females $(81.9 \%)$ (Fig. 4A). Condition (COND) explained an additional $6 \%$ of its variance in males and $7.1 \%$ in females (Fig. 4B). The remaining variability explained by the final models was accounted by accessory gland and liver mass in males (1.4\%; Figs. 4C, 4D) and by the liver mass $(2.4 \%)$ in females (Fig. 4C).

\section{Discussion}

\section{Sexual dimorphism in external morphological traits and in sonic muscle mass}

We examined the existence of sexual dimorphism in external morphological traits and in sonic muscle mass, which are associated with visual and acoustic signals used during
Fig. 3. Relation between sonic muscle mass $\left(M_{\mathrm{SM}}\right)$ and body eviscerated mass $\left(M_{\mathrm{E}}\right)$ in male $(\bigcirc)$ and female $(\bigcirc)$ Lusitanian toadfish (Halobatrachus didactylus).

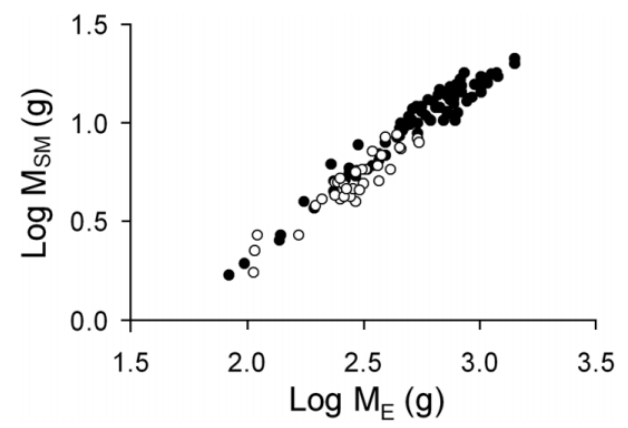

social interactions. In the breeding season, male Lusitanian toadfish defend territories centred in the nest by displaying erected fins (dorsals and pectorals), the mouth wide open, and the body raised on the pelvic fins (Vasconcelos and Ladich 2008). Territorial defence also includes chasing the intruder, biting, and mouth locking (M.C.P. Amorim and R.O. Vasconcelos, personal observation). Because the reproductive success of males depend on their ability to hold good territories, it is plausible to hypothesize that sexual dimorphism in fin and mouth size could have evolved through sexual selection favouring males with traits that are advantageous in agonistic displays (Andersson 1994), such as found in other teleosts (e.g., Oliveira and Almada 1995). Likewise, acoustic displays seem to play a major role in both agonistic and courtship contexts in the Lusitanian toadfish (dos Santos et al. 2000; Amorim et al. 2006), and males with heavier sonic muscles should also be favoured. We found differences between gender in dorsal and ventral fins but not in the pectoral fin or in mouth width. Curiously, females had longer dorsal and ventral fins than males, contrary to the expected if these fins would have an important role in the outcome of agonistic interactions. There is, however, a moderate inter- and intra-sexual size dimorphism in body size with only type I males being found at larger sizes (Modesto and Canário 2003b; Fig. 2 in this study), suggesting that a large body size is an advantage for nesting males during territorial defence. We also observed sexual dimorphism in the sonic muscles, with males having significantly heavier sonic muscles than females at a given length (approximately $25 \%$ for mean TL of $30 \mathrm{~cm}$ ), in agreement with the findings of Modesto and Canário (2003a). Consistently, external sexual 
Fig. 4. Relation between the sonic muscle mass $\left(M_{\mathrm{SM}}\right)$ and the independent variables used in the regression model for male $(\mathbf{O})$ and female (O) Lusitanian toadfish (Halobatrachus didactylus): (A) total length (TL), (B) condition (COND, the residuals of eviscerated body mass on total length), (C) residuals of liver mass on eviscerated body mass $\left(\mathrm{RM}_{\mathrm{L}}\right)$, and $(\mathrm{D})$ residuals of accessory gland mass on eviscerated body mass $\left(\mathrm{RW}_{\mathrm{AG}}\right.$, for males only). In (B), (C), and (D), the $y$ axis represents the residuals from $M_{\mathrm{SM}}$ regressed on TL, i.e., sonic muscle mass with the effect of TL removed.
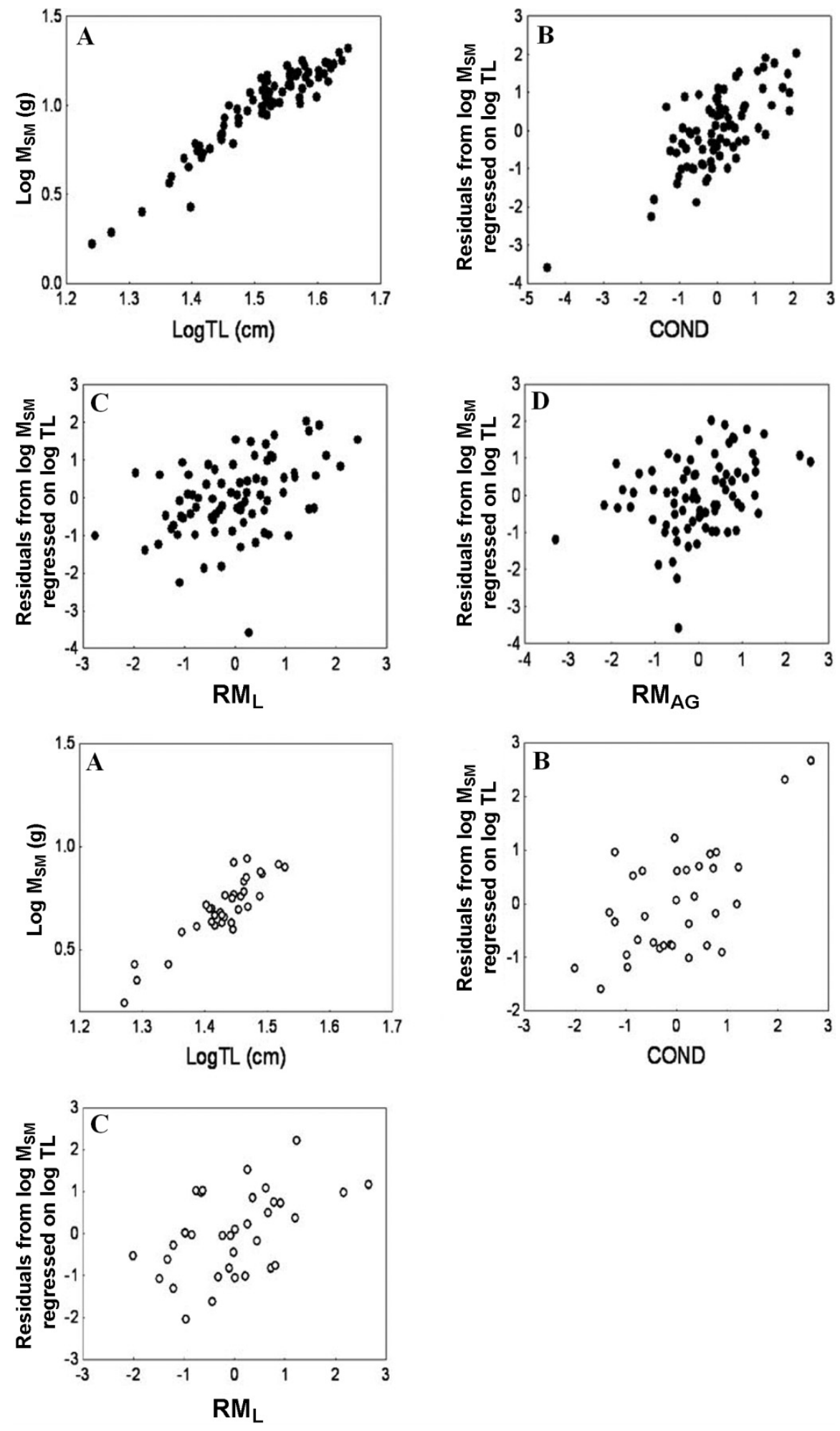

dimorphism in other batrachoidids is restricted to differences in body size and to the shape of the urogenital papilla (Brantley and Bass 1994), but differences in sonic muscle

mass between sexes can amount to $600 \%$ in plainfin midshipman (Porichthys notatus Girard, 1854), owing to the different acoustic activity shown by different gender and male 
morphotypes (Brantley and Bass 1994). This evidence suggests that in the Lusitanian toadfish and in other batrachoidids, acoustic signals and body size may reveal information about individual quality during contests and mate choice. In many species, body size and sexual secondary male traits such as acoustic signals can directly affect the outcome of male-male contests and mating success (e.g., Davies and Halliday 1978; Castellano et al. 2000).

The sexual dimorphism in sonic muscle mass found in this study is consistent with the findings of Modesto and Canário (2003a), which reported that swim-bladder mass (swim bladder plus embedded sonic muscles) shows sexual polymorphism, i.e., it is larger in type I males, intermediate in type II males, and smaller in females. Sexual dimorphism in the swim bladder, sonic muscle fibres, and neural circuitry of sound production is typical among batrachoidids (Fine et al. 1984, 1990; Modesto and Canário 2003b; see review in Bass and McKibben 2003) and suggests that acoustic communication plays a prevalent role over other channels of communication and is essential for reproduction in the Lusitanian toadfish as in other batrachoidids (Bass and McKibben 2003). Curiously, we found that the CV for sonic muscle mass in males was only $7 \%$ higher than in females. Considering that our samples included nonspawners and that only males experience sonic muscle hypertrophy associated with the breeding season (Modesto and Canário 2003a), it was expected that females would show less variability than males in the mass of sonic muscles. The lack of a sharper difference between genders could reflect the relatively low sonic muscle sexual dimorphism and also the possibility that females have a higher vocal activity than traditionally described.

\section{Traits affecting sonic muscle variability}

This study showed that there is considerable variation in sonic muscle mass both in males $(\mathrm{CV}=40 \%)$ and in females $(\mathrm{CV}=33 \%)$. Multiple regression analysis revealed that body length and condition were good indicators of sonic muscle mass in both gender. These results are consistent with those of Modesto and Canário (2003a), which showed that swim-bladder mass increases with body size (eviscerated body mass) in mature and immature specimens of this species. Accordingly, swim bladder and associated sonic muscles show continuous growth in other batrachoidids (Fine et al. 1990; Brantley et al. 1993a). Sonic muscle mass of spawning cod has also been reported to be positively associated not only with body size and condition but also with fertilization potential (Rowe and Hutchings 2004), suggesting that acoustic features associated with sonic muscle mass also reveal information about individual quality in this vocal species. Likewise, in other taxa, acoustic cues such as sound frequency or acoustic repertoire size are related to body mass and (or) condition (e.g., Davies and Halliday 1978; Clutton-Brock and Albon 1979; Mager et al. 2007). For example, male common loons (Gavia immer (Brünnich, 1764)) in better condition and of larger body mass produce lower frequency sounds (yodels) during territorial defence (Mager et al. 2007). Mager and colleagues have shown with a playback experiment that lower frequency calls elicit stronger reactions from receivers, suggesting that dominant frequency of the yodel may honestly communicate fighting ability (Mager et al. 2007).
Residuals of liver mass gave a minor (1\%-2\%) but significant contribution to explain sonic muscle mass variability in both genders of Lusitanian toadfish. Both condition and hepatosomatic indices (analogous to the residuals of eviscerated body mass and liver mass used in the present study) are thought to represent good measures of condition in fish (Chellappa et al. 1995) and show minimal values at the end of the breeding season in the Lusitanian toadfish, probably associated to gamete production in females and to the increased metabolic needs of territorial defence and vocal activity in males (Modesto and Canário 2003b). Likewise the residuals of accessory gland mass contributed to sonic muscle mass in males. These glands are responsible for the exocrine production of mucosubstances, which seems to be a common feature of batrachoidids and of many other teleost species, and are thought to embed sperm and create sperm trails to reduce sperm dispersion (Barni et al. 2001). This would increase the chances of fertilizing females eggs in the nest by type I males, who have considerable larger accessory glands than type II males (Modesto and Canário $2003 b$ ). Nesting males with larger accessory glands may therefore gain higher chances of providing parental care to a higher percentage of own offspring than males with smaller accessory glands. Interestingly, the residuals of gonad mass did not enter in the final model, although it shows a similar seasonal variation as sonic muscle and accessory gland mass (Modesto and Canário 2003a).

Acoustic signals have a relevant role in the mating system of different taxa, allowing animals to convey information about their quality as mates, competitors, or both (Andersson 1994). Although fish are probably the largest group of sound-producing vertebrate, having evolved an outstanding variety of sonic organs, the functional role of their signals remains largely unknown, especially when comparing with the wealth of knowledge existent for other taxa (Ladich 2004; Ladich and Fine 2006). The present study shows that the variability of the sonic muscle mass could indicate individual quality in the Lusitanian toadfish, namely larger body size and better condition (somatic and liver) in both males and females and larger accessory glands in males. In batrachoidids, larger males with heavier sonic muscles show higher calling capabilities and emit sounds with higher amplitude (Fine et al. 2001; Vasconcelos and Ladich 2008). Frequency of sound is imparted by sonic muscle contraction rather than swim-bladder resonance, and it does not vary with fish size in the oyster toadfish (Opsanus tau (L., 1766)) (Fine et al. 2001), although grunt dominant frequency decreases with fish size in the Lusitanian toadfish (Vasconcelos and Ladich 2008). Females approaching a Lusitanian toadfish chorus could thus potentially select a better quality male based on acoustic cues, such as calling rate or call amplitude. Likewise males could judge their opponents based on grunt amplitude and dominant frequency. Future work is needed to associate calling rate and acoustic characteristics of sounds with sonic muscle mass and reproductive success to further support our conclusions.

\section{Acknowledgement}

We thank Montijo local fishermen for providing the specimens used in this study and Paulo Fonseca and Yorgos Stratoudakis for providing valuable comments on the manu- 
script. This study was supported by Ministério da Ciência, Tecnologia e Ensino Superior (Portugal) with the project PDCT/MAR/58071/2004 and the Fundação para a Ciência e a Tecnologia grants (SFRH/BD/30491/2006 to R.O.V. and SFRH/BPD/14570/2003 to M.C.P.A.).

\section{References}

Amorim, M.C.P. 2006. Diversity of sound production in fish. In Communication in fishes. Edited by F. Ladich, S.P. Collin, P. Moller, and B.G. Kapoor. Science Publishers, Enfield, N.H. pp. 71-104.

Amorim, M.C.P., McCracken, M.L., and Fine, M.L. 2002. Metabolic costs of sound production in the oyster toadfish, Opsanus tau. Can. J. Zool. 80(5): 830-838. doi:10.1139/z02-054.

Amorim, M.C.P., Vasconcelos, R.O., Marques, J.F., and Almada, F. 2006. Seasonal variation of sound production in the Lusitanian toadfish, Halobatrachus didactylus. J. Fish Biol. 69(6): 1892-1899. doi:10.1111/j.1095-8649.2006.01247.x.

Amorim, M.C.P., Simões, J.M., and Fonseca, P.J. 2008. Acoustic communication in the Lusitanian toadfish, Halobatrachus didactylus: evidence for an unusual large vocal repertoire. J. Mar. Biol. Assoc. U.K. 88(05): 1069-1073. doi:10.1017/ S0025315408001677.

Andersson, M. 1994. Sexual selection. Princeton University Press, Princeton, N.J.

Barimo, J.F., and Fine, M.L. 1998. Relationship of swim-bladder shape to the directionality pattern of underwater sound in the oyster toadfish. Can. J. Zool. 76(1): 134-143. doi:10.1139/cjz76-1-134.

Barni, A., Mazzoldi, C., and Rasotto, M.B. 2001. Reproductive apparatus and male accessory structures in two batrachoid species (Teleostei, Batrachoididae). J. Fish Biol. 58(6): 1557-1569. doi:10.1111/j.1095-8649.2001.tb02312.x.

Bass, A.H., and McKibben, J.R. 2003. Neural mechanisms and behaviors for acoustic communication in teleost fish. Prog. Neurobiol. 69(1): 1-26. doi:10.1016/S0301-0082(03)00004-2. PMID: 12637170.

Bee, M.A., Perrill, S.A., and Owen, P.C. 1999. Size assessment in simulated territorial encounters between male green frogs (Rana clamitans). Behav. Ecol. Sociobiol. 45(3-4): 177-184. doi:10. 1007/s002650050551.

Bradbury, J.W., and Vehrencamp, S.L. 1998. Principles of animal communication. Sinauer Associates, Inc., Sunderland, Mass.

Brantley, R.K., and Bass, A.H. 1994. Alternative male spawning tactics and acoustic signals in the plainfin midshipman fish Porichthys notatus Girard (Teleostei, Batrachoididae). Ethology, 96: 213-232.

Brantley, R.K., Tseng, J., and Bass, A.H. 1993a. The ontogeny of inter- and intrasexual vocal muscle dimorphisms in a soundproducing fish. Brain Behav. Evol. 42(6): 336-349. doi:10.1159/ 000114170. PMID:8275300.

Brantley, R.K., Marchaterre, M.A., and Bass, A.H. 1993b. Androgen effects on vocal muscle structure in a teleost fish with interand intra-sexual dimorphism. J. Morphol. 216(3): 305-318. doi:10.1002/jmor.1052160306. PMID:8315650.

Castellano, S., Rosso, A., Laoretti, F., Doglio, S., and Giacoma, C. 2000. Call intensity and female preferences in the European green toad. Ethology, 106(12): 1129-1141. doi:10.1046/j.14390310.2000.00639.x.

Chellappa, S., Huntingford, F.A., Strang, R.H.C., and Thomson, R.Y. 1995. Condition factor and hepatosomatic index as estimates of energy status in male three-spined stickleback. J. Fish Biol. 47(5): 775-787. doi:10.1111/j.1095-8649.1995.tb06002.x.
Clutton-Brock, T.H., and Albon, S.D. 1979. The roaring of red deer and the evolution of honest advertisement. Behaviour, 69(3): 145-170. doi:10.1163/156853979X00449.

Cohen, M.J., and Winn, H.E. 1967. Electrophysiological observations on hearing and sound production in the fish, Porichthys notatus. J. Exp. Zool. 165(3): 355-369. doi:10.1002/jez. 1401650305. PMID:6076901.

Connaughton, M.A., Taylor, M.H., and Fine, M.L. 2000. Effects of fish size and temperature on weakfish disturbance calls: implications for the mechanism of sound generation. J. Exp. Biol. 203(9): 1503-1512. PMID:10751166.

Davies, N.B., and Halliday, T.R. 1978. Deep croaks and fighting assessment in toads Bufo bufo. Nature (London), 274(5672): 683-685. doi:10.1038/274683a0.

dos Santos, M.E., Modesto, T., Matos, R.J., Grober, M.S., Oliveira, R.F., and Canário, A. 2000. Sound production by the Lusitanian toadfish, Halobatrachus didactylus. Bioacoustics, 10: 309-321.

Engen, F., and Folstad, I. 1999. Cod courtship song: a song at the expense of dance? Can. J. Zool. 77(4): 542-550. doi:10.1139/ cjz-77-4-542.

Fine, M.L., and Pennypacker, K.R. 1986. Hormonal basis for sexual dimorphism of the sound-producing apparatus of the oyster toadfish. Exp. Neurol. 92(2): 289-298. doi:10.1016/00144886(86)90081-6. PMID:3956662.

Fine, M.L., Economos, D., Radtke, R., and McClung, J.R. 1984. Ontogeny and sexual dimorphism of the sonic motor nucleus in the oyster toadfish. J. Comp. Neurol. 225(1): 105-110. doi:10. 1002/cne.902250111. PMID:6725634.

Fine, M.L., Burns, N.M., and Harris, T.M. 1990. Ontogeny and sexual dimorphism of sonic muscle in the oyster toadfish. Can. J. Zool. 68(7): 1374-1381. doi:10.1139/z90-205.

Fine, M.L., Malloy, K.L., King, C.B., Mitchell, S.L., and Cameron, T.M. 2001. Movement and sound generation by the toadfish swimbladder. J. Comp. Physiol. A Neuroethol. Sens. Neural Behav. Physiol., 187(5): 371-379. doi:10.1007/s003590100209. PMID:11529481.

Grafen, A. 1990. Sexual selection unhandicapped by the Fisher process. J. Theor. Biol. 144(4): 473-516. doi:10.1016/S00225193(05)80087-6. PMID:2402152.

Hasselquist, D.S., Bensch, S., and von Schantz, T. 1996. Correlation between male song repertoire, extra-pair paternity and offspring survival in the great reed warbler. Nature (London), 381(6579): 229-232. doi:10.1038/381229a0.

Knapp, R., Wingfield, J.C., and Bass, A.H. 1999. Steroid hormones and paternal care in the plainfin midshipman fish (Porichthys notatus). Horm. Behav. 35(1): 81-89. doi:10.1006/hbeh.1998. 1499. PMID:10049606.

Ladich, F. 2004. Sound production and acoustic communication. In The senses of fish: adaptations for the reception of natural stimuli. Edited by G. von der Emde, J. Mogdans, and B.G. Kapoor. Narosa Publishing House, New Delhi, India. pp. 210-230.

Ladich, F., and Fine, M.L. 2006. Sound-generating mechanisms in fishes: a unique diversity in vertebrates. In Communication in fishes. Edited by F. Ladich, S.P. Collin, P. Moller, and B.G. Kapoor. Science Publishers, Enfield, N.H. pp. 1-43.

Mager, J.N., III, Walcott, C., and Piper, W.H. 2007. Male common loons, Gavia immer, communicate body mass and condition through dominant frequencies of territorial yodels. Anim. Behav. 73(4): 683-690. doi:10.1016/j.anbehav.2006.10.009.

Márquez, R., Bosch, J., and Eekhout, X. 2008. Intensity of female preference quantified through playback setpoints: call frequency versus call rate in midwife toads. Anim. Behav. 75(1): 159-166. doi:10.1016/j.anbehav.2007.05.003. 
Maynard Smith, J., and Harper, D. 2003. Animal signals. Oxford University Press, Oxford.

Mitchell, S., Poland, J., and Fine, M.L. 2008. Does muscle fatigue limit advertisement calling in the oyster toadfish Opsanus tau? Anim. Behav. 76(3): 1011-1016. doi:10.1016/j.anbehav.2008. 03.024.

Modesto, T., and Canário, A.V.M. 2003a. Hormonal control of swimbladder sonic muscle dimorphism in the Lusitanian toadfish Halobatrachus didactylus. J. Exp. Biol. 206(19): 34673477. doi:10.1242/jeb.00581. PMID:12939377.

Modesto, T., and Canário, A.V.M. 2003b. Morphometric changes and sex steroid levels during the annual reproductive cycle of the Lusitanian toadfish, Halobatrachus didactylus. Gen. Comp. Endocrinol. 131(3): 220-231. doi:10.1016/S0016-6480(03) 00027-3. PMID: 12714003.

Myrberg, A., Ha, S., and Shamblott, M. 1993. The sounds of bicolor damselfish (Pomacentrus partitus): predictors of body size and a spectral basis for individual recognition and assessment. J. Acoust. Soc. Am. 94(6): 3067-3070. doi:10.1121/1.407267.

Oliveira, R.F., and Almada, V.C. 1995. Sexual dimorphism and allometry of external morphology in Oreochromis mossambicus. J. Fish Biol. 46: 1055-1064.
Prestwich, K.N. 1994. Energy and constraints to acoustic communication in insects and anurans. Am. Zool. 94: 625-643.

Remage-Healey, L., and Bass, A.H. 2005. Rapid elevations in both steroid hormones and vocal signaling during playback challenge: a field experiment in Gulf toadfish. Horm. Behav. 47(3): 297305. doi:10.1016/j.yhbeh.2004.11.017. PMID:15708758.

Rowe, S., and Hutchings, J.A. 2004. The function of sound production by Atlantic cod as inferred from patterns of variation in drumming muscle mass. Can. J. Zool. 82(9): 1391-1398. doi:10.1139/z04-119.

Taigen, T.L., and Wells, K.D. 1985. Energetics of vocalization by an anuran amphibian (Hyla versicolor). J. Comp. Physiol. B Biochem. Syst. Environ. Physiol. 155: 163-170.

Vasconcelos, R.O., and Ladich, F. 2008. Development of vocalization, auditory sensitivity and acoustic communication in the Lusitanian toadfish Halobatrachus didactylus. J. Exp. Biol. 211(4): 502-509. doi:10.1242/jeb.008474. PMID:18245626.

Zahavi, A. 1975. Mate selection — a selection for a handicap. J. Theor. Biol. 53(1): 205-214. doi:10.1016/0022-5193(75)901113. PMID:1195756. 